\title{
COMPUTER SIMULATIONS, DISCLOSURE AND DUTY OF CARE
}

\author{
John Barlow \\ School of Arts and Sciences (NSW) \\ Australian Catholic University \\ Strathfield, NSW, AUSTRALIA
}

\begin{abstract}
Computer simulations provide cost effective methods for manipulating and modeling 'reality'. However they are not real. They are imitations of a system or event, real or fabricated, and as such mimic, duplicate or represent that system or event. The degree to which a computer simulation aligns with and reproduces the 'reality' of the system or event it attempts to mimic or duplicate depends upon many factors including the efficiency of the simulation algorithm, the processing power of the computer hardware used to run the simulation model, and the expertise, assumptions and prejudices of those concerned with designing, implementing and interpreting the simulation output. Computer simulations in particular are increasingly replacing physical experimentation in many disciplines, and as a consequence, are used to underpin quite significant decision-making which may impact on 'innocent' third parties. In this context, this paper examines two interrelated issues: Firstly, how much and what kind of information should a simulation builder be required to disclose to potential users of the simulation? Secondly, what are the implications for a decision-maker who acts on the basis of their interpretation of a simulation output without any reference to its veracity, which may in turn comprise the safety of other parties?

KEYWORDS: Modeling and simulation, ethics, disclosure, duty of care, responsibility.
\end{abstract}

\section{INTRODUCTION}

In general terms a model may be described as a representation of the connected variables, or conditions, that are assumed to be operating within a system or an event while a simulation may be described as an attempted reproduction, using a model, of the conditions that define a system or event. However, in many instances though, both terms are used to mean the same thing.

There are numerous types of models which are used for different purposes. In science, for example, Barbour (1974, pp 29 - 30) suggests four: experimental models which can be constructed and used, logical models which are used to illustrate abstract systems, mathematical models which are generally symbolic representations of quantitative variables, and theoretical models which are described as "imaginative mental constructs invented to account for observed phenomenon." All these models can be used as the basis for building computer simulations. Computer-based simulations may, at one level, involve the use of 'unsophisticated' spreadsheet and database applications to simulate and predict events that can, in the main, be conveniently modeled using mathematical relationships. For many people however, a computer-based simulation often means a multimedia application, such as a virtual reality application which provides them with the opportunity to 'experience' various situations, using the computational power of modern computer 
platforms, and their associated user and graphical interfaces, to generate interactive images of 'very real' situations.

Numerous authors have provided definitions of computer-based modeling and simulation, together with descriptions of where they are used in various human activities. Essentially there are a number of themes that run through these definitions, the most notable of which is the notion that simulations provide cost effective methods for manipulating and modeling 'reality'. There are many instances that illustrate this view. For example, architectural design simulations, which permit prospective buyers to walk through a new home design, are now frequently used as marketing tools. Metallurgists are cautiously hopeful that the combination of more sophisticated simulation algorithms combined with increased computer processing power will further enhance their understanding of crack propagation in metals. In reality, computer-based simulations are utilised in just about every human endeavour including playing games for pleasure and entertainment, modeling courtroom evidence and complex experimental data, graphing philosophical paradoxes, and providing sophisticated modeling mechanisms for predicting the weather! In addition simulations are used in many application areas, most notably defence applications where, for example, military scenarios can be modelled and evaluated without the need to subject military personnel to real and potentially hazardous combat conditions.

Markovsky and Jin (2002, p 1), for example, suggest a model is a "set of variables and the functional relationship among them. ... A model contains at least one independent variable and one dependent variable, where a change in the former is linked to change [or an outcome] in the latter", while a computer simulation is a "program whose variables and functional relationships are intended by its author to map onto empirical phenomenon and processes." Shelly, Cashman \& Vermaat (2002, p 6.43), suggest computer simulations are computer-based models of real-life situations. Computer applications of models and simulations are used to support computer-aided decision-making associated with such activities as design, testing, planning, and control. Ören (2000, p 166) suggests simulation can be defined as goal-driven experimentation with dynamic models. He argues that the reasons for using simulation vary with the type of area of study and briefly sets out a number of examples. These include analysis problems where simulation is used to provide insight, continuous simulation used as part of the design process (particularly in engineering design), and discrete simulation used in association with business applications. Other instances include artificial intelligence applications used in simulation software, autonomous software agents, Internet simulations using local, or network computational platforms, as well as defence applications as noted above.

Singh (1996, pp 560-561), has adopted the combined term, 'simulation model', and defines it as a concise framework for the analysis and understanding of a system that facilitates imitating the behaviour of the system over time. He asserts that simulation-modeling techniques are powerful and cost effective tools for manipulating time, system inputs, and the logic combinations associated with complex systems. Moreover, when combined with visual animation equipment simulation modeling techniques provide an efficient means of learning about, experimenting with, and analysing real-life complex systems.

One of the important considerations of Singh's definition relates to the observation that simulation is synonymous with imitation, and while his work is strictly focused in the context of complex computer integrated manufacturing and design systems, it has merit in the wider context of computer modeling and simulation. It is an important observation in that it underlines the important, if not cautionary point that computer simulations are not real, they are imitations of a system or event, real or fabricated, and as such mimic, duplicate or represent that system or event. This point is supported 
by Markovsky and Jin (2002, p 2) when they assert that computer simulations are "at best virtual experiments yielding virtual data". The degree to which a computer simulation actually aligns with and reproduces the 'reality' of the system or event it is attempting to mimic or duplicate is dependent upon many factors. These factors include, but are not limited to, the efficiency of the simulation algorithms, the processing power of the computer hardware used to run the simulation model, and most importantly the expertise, assumptions and prejudices of those concerned with designing, implementing, and interpreting the output of models and simulations. In this context, Boumans (1999, p 93) argues that models in particular integrate more than just theory and data. That is, the veracity of a model, and hence any simulation derived from it, is dependent upon a complicated amalgamation and integration of many competing influences, including theoretical notions, mathematical concepts, mathematical techniques, stylized facts, empirical data, policy views, analogies, and metaphors. Moreover, it could be argued that these competing influences can impact on a model builder's deliberations at both a conscious and perhaps more crucially, an unconscious level, particularly where the focus of the model and simulation building activity is restricted to demonstrating and applying 'intellectual' skills and knowledge. This implies the need for a more considered and reflective approach to the use of models and simulations more generally.

\section{CODES OF PROFESSIONAL ETHICS AND PROFESSIONAL PRACTICE}

Codes of professional ethics and professional practice of various organisations provide a set of guidelines for the conduct of their members. The two codes are notionally differentiated by their intent. Codes of ethics are intended to provide fundamental guidance, which should permeate the conduct of an organisation's members, while the code of practice is designed to provide more specific guidelines regarding acceptable standards of professional practice. Essentially the development and adoption of codes of ethics and practice by organised groups reflect their desire, in part, to be seen and accepted as 'professional' entities in the wider community, and their member's as 'experts' in their chosen field.

The expanding importance and scope of the various application areas of modelling and simulation has prompted the call for the establishment of a professional code of ethics for those involved in the development of computer-based simulations. Mulvey (1994, p 54) argued in the context of computer modeling that since the actions of modelers can impact on others "codes of ethical conduct represent attempts to reduce harm when professionals carry out their business". This view is supported by Ören (2002a) who has suggested that, given the expanding importance of their work, simulators are now obliged to reflect on the professional and ethical implications of their work. Ören $(2002 b)$ has asserted that a code of professional ethics should be formulated and adopted for simulators since ethics was the missing link between serious validation as well as verification studies of modelling and simulation. He argued that since simulation studies could affect numerous people as well as the environment in many different ways, those involved in any aspect of it should reflect upon their responsibilities. Further, simulations are used in many disciplines, such as research, scientific and engineering applications, and business, where specific codes of professional ethics and practice already exist and as such simulators should, at the very least, be aware of such codes. He also suggested that various simulation societies should provide leadership in urging their members to adopt a code of professional ethics so that their members "can show the acceptance of their responsibilities and accountabilities."

A Code of Professional Ethics for Simulationists (SimEthics) has since been established by the Society for Modeling and Simulation International. This is a voluntary code and is no doubt an important development given the nature of the interaction between computers, simulators, computer 
applications, and the general public. Ferguson (1992) [quoted by Beder (1998, p 49)], for example, asserts that commercial software programs are becoming increasingly available for all sorts of design problems. These programs, argues Ferguson, offer 'illusions of certainty' without reducing the need for human judgment requiring 'intimate, first hand internalized knowledge' of the technology being used and the impact that this might have on product outcomes, a view supported by Girill (2002). The real issue of course in this instance is how such codes can be implemented and used to guide the professional practice of simulators. One issue worth exploring in this context is the need for the disclosure of information about a simulation and the associated duty of care implications.

\section{DISCLOSURE AND DUTY OF CARE}

The need for the disclosure of information associated with simulations is an emerging issue. That is, how much information should a simulator be compelled to inform their colleagues and potential users, both from within the professional and public domains, about the limitations and assumptions underpinning the development of a simulation? The quality of a simulation is very much dependent upon the quality of the model it has been developed from, which implies of course that it is fundamentally dependent upon the quality of the data used to develop and test both the model and simulation. In addition, there is also an argument relating to the right, or perhaps even more importantly responsibility, of a simulation user to know what the simulation package is actually designed to model, and how it should be interpreted and applied. This should include information about the context, circumstances, and design constraints associated with the development of the model, the range and type of testing data used to verify the validity and reliability of the simulation, as well as information indicating the intended applications of the simulation.

Girill (1999), for example, has noted, "software trends already underway make computer documentation the next major venue for the appropriate disclosure of relevant facts that once might have remained hidden." He observed that sophisticated computer simulations in particular are increasingly replacing physical experimentation in many disciplines, such as engineering and medicine, and as a consequence are used to underpin quite significant decision-making. In essence the decision-maker is increasingly vulnerable to the quality and appropriateness of the assumptions the software programmer has made when developing the simulation. Girill (1999) makes an important point when he asserts:

Disclosing hidden software assumptions, and spelling out their implications for the output of simulation runs, will have a major impact on how astutely engineers and physicians can make good judgements based on simulated, rather than physical analysis.

Users, and in particular uncritical users and third parties such as members of the 'public' not directly involved in the building, implementation and interpretation of models and simulations, are very much dependent upon the competence and professional expertise of simulation builders and users. These individuals would probably have not seen it necessary, or perhaps not even been aware that they should have, carried out some form of risk assessment in relation to the model, the simulation, the output, and the interpretation of the output by 'experts'. They are thus forced into a trust relationship between themselves and the expert simulation builders and users, implying that they believe them to be honest and true, which also significantly implies a degree of dependency and vulnerability. This point has been noted by Fullinwider, (1995, p 2) as one of three that distinguishes a profession, the other two being an orientation to public good, and a specialized knowledge and training, and has clear duty of care implications. 
Duty of care requires all individuals to do what is reasonable to protect the wellbeing of others. For example, a legal duty of care is placed on all employers, their employees and any others, including contractors, to do everything reasonably practicable to protect the health and safety of all individuals from hazards in a workplace. A professional duty of care also involves harm minimization, acting in a client's best interest and exercising discretionary power responsibly. In particular, Ören (2002a) has suggested that the major components of professionalism in modelling and simulation are knowledge, activities, and behaviour. That is, according to Ören (2002a), "knowledge is essential to perform the activities which in turn should be based on acceptable behaviour".

Manufacturers and suppliers of consumable goods have a duty to provide products that do not compromise the safety of consumers. Indeed, legislation imposes statutory warranties of fitness for purpose which are contractually binding between seller and purchaser. The use of any product though involves an inherent degree of risk. Heckman and Wobbrock (1998, p 394) assert:

Strict products liability recognizes that with modern technology and mass production, injuries will occur without intentional misdeed and despite reasonable care.

By implication then individuals and organizations that provide computer models and simulations, also have a duty to provide products that maintain the safety and wellbeing of others. That said, the nature of the risks can vary significantly over a wide range of issues, including for example, an inherently defective product produced without reference to new methods and standards, misinterpretation of output, or inappropriate use occasioned by the provision of poor, inappropriate or no training of users. Like other products, faulty simulation products can result in negligence actions. There are various legal options available for defending charges of negligence, and in relation to computer usage in particular there appears to be no clear standards (Nissenbaum, 1994, 1996). However this should be no excuse. It would seem reasonable to argue that all builders and users of computer simulations, and in particular those who would identify themselves as experts and members of a professional body, should exercise as an inherent code of practice, a moral responsibility for their products.

Weckert \& Adeney (1997, p 89) argue that "experts have a responsibility to be careful, competent, and honest in their work" and that the word "responsible" has two important senses: causal (cause and effect) and accountability (liability). Hart (1985) [quoted by Coleman (2005)] has suggested a broader interpretation of responsibility identifying four senses. These are:

- Role-responsibility (the performance or fulfillment of the duties attached to a person's social role),

- Causal-responsibility (a retrospective sense of responsibility relating cause and effect between a person's actions and the consequences of them),

- Liability-responsibility (responsibility for causing harm in violation of the law), and

- Capacity-responsibility (the capacity to understand the conduct required by relevant societal norms, and then to act appropriately).

Coleman (2005) writing in the context of computer systems generally has suggested these senses 'provide a framework for exploring computers and moral responsibility'. These include: a retrospective analysis of 'who is responsible for computer use', the anticipation and prevention of future problems, a consideration of whether computers could be responsible, and an assessment of the decisions computers should not be allowed to make. She also provides a very useful analysis of the difficulties associated with identifying who are the responsible parties in relation to computer use, which centres on four barriers to responsibility identified by Nissenbaum $(1994,1996)$ :

- The problem of many hands,

- Bugs, 
- Blaming the computer, and

- Ownership without liability, as well as two others:

- Poor articulation of norms, and

- Assumption of ethical neutrality.

A summary of Coleman's analysis is set out in table 1.

\begin{tabular}{|c|c|}
\hline Barrier & Description \\
\hline Problem of many hands & $\begin{array}{l}\text { Complex computer systems are produced by groups making it } \\
\text { difficult to identify who is responsible for errors and harmful } \\
\text { consequences of use. }\end{array}$ \\
\hline Bugs & $\begin{array}{l}\text { 'Bugs' and 'computer error' are preferred to 'programmer } \\
\text { error' discouraging humans from interpreting these errors as } \\
\text { their own (Gotterban, 2001). }\end{array}$ \\
\hline Blaming the computer & $\begin{array}{l}\text { A computer is often the proximate cause of harm. } \\
\text { People often attribute intentionality to computers. } \\
\text { People have 'delegated' or 'abdicated' their decision making } \\
\text { to computers (Ladd, 1989, p 219). } \\
\text { People have high expectations of computers (Johnson \& } \\
\text { Mulvey, 1995). } \\
\text { Once computers are blamed there is no need to investigate } \\
\text { other human factors. }\end{array}$ \\
\hline $\begin{array}{l}\text { Ownership without } \\
\text { liability }\end{array}$ & $\begin{array}{l}\text { Extending the privileges and rights of ownership of software } \\
\text { systems without demanding owners accept responsibility for } \\
\text { their products (Nissenbaum, 1994, 1996). }\end{array}$ \\
\hline $\begin{array}{l}\text { Poor articulation of } \\
\text { norms }\end{array}$ & $\begin{array}{l}\text { A poor understanding of what each party in the creation, } \\
\text { implementation, and use of a system is responsible for doing } \\
\text { (Johnson \& Mulvey, 1995). }\end{array}$ \\
\hline $\begin{array}{l}\text { Assumption of ethical } \\
\text { neutrality }\end{array}$ & $\begin{array}{l}\text { Problems and solutions are articulated and developed in a } \\
\text { context in which their impact on humanity is less visible than } \\
\text { it should be (Gotterban, 2001). }\end{array}$ \\
\hline
\end{tabular}

Table 1: Responsibility barriers

\section{DISCUSSION}

Clearly disclosure and duty of care are complex matters. For example, not only how much and what type of information should be disclosed is important, but also to whom should it be reasonably disclosed (colleagues, independent referees, members of the public)? In addition issues associated with intellectual property, the copyright and patenting of new simulation systems, and the possibility of industrial and international espionage especially given the increasing reliance by the defence sector on the use of computer-based simulations are also worthy of attention. 
A further issue related to disclosure and candour centres on the substance of the detail contained in the information to be released. Even partial disclosure of the rationale underlying a model might result in an increase in the authority and mystique associated with the use of and results generated by the simulation which may be totally unwarranted and which may lead to unintended harm. Disclosure may provide a simulation with a 'credibility aura' well beyond its actual merits, particularly in the public domain where knowledge of the mathematical assumptions and other theories underpinning the simulation design and implementation is either non-existent or perhaps little understood. It may also result in the reverse.

Sterman (1991, p 209), observes that most people are not able to make judgments about the veracity of computer models in an intelligent and informed manner, and makes the point that computer models can be misused, accidentally or intentionally:

Thus there have been many cases in which computer models have been used to justify decisions already taken, to provide a scapegoat when a forecast turned out wrong, or to lend specious authority to an argument.

A basic consideration here is who is ultimately accountable in these circumstances if a decision made on the basis of a simulation results in harm to an individual or group either directly or indirectly? Where does the duty of care lie?

Weckert \& Adeney (1997, p 91) have set out three conditions for establishing accountability. These can be interpreted as: control, intention, and free choice. It would seem reasonably obvious then that the misuse of computer simulations might hold the individuals concerned liable to account for their actions, assuming of course that they have not been coerced. This is an important consideration given the quite often deliberate, or otherwise, assertions of 'experts' reporting the results of their work, or politicians and government spokespeople explaining a controversial public policy matter, emphasizing the use of computer modeling and simulations to substantiate and support their assertions and arguments. This may directly or indirectly provide their assertions and arguments with a degree of implied authenticity and authority. There is a possible argument for suggesting that uncritical public trust or confidence in the authority of an expert who suggests, directly or even indirectly, they are using a computer model to support and validate an argument or observation might be somewhat naive and misplaced. Perhaps the question is really this: Is it the implied or actual use of the computer, or the model and simulation, or both, which assigns credibility to the expert advice? The simple reality is, as already noted above, the quality of the output generated by a computer-based model or simulation is critically dependent on the quality of the data used and the manner in which it was designed and implemented, not necessarily because it was modeled in a computer, even allowing for the fact that modern super computers undoubtedly provide a means for very sophisticated and rigorous modeling and simulations in real time.

Sterman (1991, p 209) has argued that whether members of society like it or not they are all becoming consumers of computer models. Importantly he observed:

The ability to understand and evaluate computer models is fast becoming a prerequisite for the policymaker, legislator, lobbyist, and citizen alike.

That is, all members of society will need, to some extent, be prepared to accept the responsibility of carrying out some form of appropriate due diligence. In order for this to occur though, a supportive and perhaps even enforceable structure needs to be developed. One way forward here might be the consideration of a 'boundaries of responsibility' concept. This could be based on agreed need to know (or entitlement to know) protocols, which set out the type of information that should be reasonably disclosed, by whom and to whom, at each simulation design and implementation stage. 
A possible research focus might involve the development and implementation of a set of information 'boundaries' which outline the rights, entitlements, and responsibilities of simulators and various application users and consumers (including the public domain), so that all concerned are afforded the opportunity to make reasoned, independent and critical decisions about the merits, or otherwise, of the output and use of computer-based simulations if they so choose. Clearly this may have significant professional practice implications for simulators, as well as those who use simulation 'tools' as part of their daily responsibilities, be they employment based or otherwise. At a basic level, the 'boundaries of responsibility' proposal looks very much like another code of practice, and might well be so. However it does suggest the incorporation of groups beyond the simulation profession, such as simulation users and public consumers, who also make decisions, both directly and indirectly, based on the work of simulators. Coleman (2005) has provided three recommendations for overcoming the series of barriers to responsibility noted earlier which may help to support and regularize this process. These are:

- Ensuring understanding of (and assumptions about) responsibility is appropriate for the task by using the practice of responsibility to improve both practice and technology.

- Re-designing computer systems to reveal that they are not responsible.

- Articulating those norms most relevant to the creation, implementation, and use of computer systems.

One final point: mistakes can and do occur. Coyle (1977) [quoted by Coyle and Exelby (2000, p 32)] states 'there are almost endless opportunities for making mistakes in any kind of model building', but as Heckman \& Wobbrock (1998, p 399) have asserted:

"Humans should be responsible for the actions of their creations."

Notwithstanding they were writing specifically in the context of autonomous agents, their assertion is relevant to the moral and professional responsibilities the wider modeling and simulation community should be prepared to accept.

\section{CONCLUSION}

In the context of professional practice, the need for disclosure and duty of care were examined as matters which needed further consideration in the development and implementation of computer models and simulations. It was suggested that all simulation builders and users should be prepared to exercise an inherent moral responsibility for their work.

\section{REFERENCES}

Andradóttir, S., Healy, K. J., Withers, D. H. \& Nelson, B. L. (eds) (1997) Proceedings of the 1997 Winter Simulation Conference.

Barbour, I. G. (1974) Myths, Models and paradigms The Nature of Scientific and Religious Language, SCM Press, London.

Barney, G. O., Kreutzer, W. B. \& Garrett, M. J. (eds) (1991) Managing a Nation The Microcomputer Software Catalog $2^{\text {nd }}$ ed, Westview Press, Boulder.

Beder, S. (1998) The New Engineer. Management and Professional Responsibility in a Changing World, Macmillan, South Yarra.

Boumans, M. (1999) “Built-in justification”, in Morgan and Morrison (1999), pp 66 - 96. 
Coleman, K. G. (2005) “Computing and Moral Resonsibility”, The Standford Encyclopedia of Philosophy (Spring edition), Edward N. Zalta (ed).

(http://plato.stanford.edu/archives/spr2005/entries/computing-responsibility accessed 10 August, 2005)

Coyle, R. G. (1977) Management Systems Dynamics, Wiley, Chichester, in Coyle, G. \& Exelby, D. 2000.

Coyle, G. \& Exelby, D. (2000) “The validation of commercial system dynamics models”, System Dynamics Review, Vol. 16, No. 1 (Spring), pp 27-41.

Fullinwider, R. (1995) "Professional codes and moral understanding”, Res Publica, 4, pp 1-6.

Girill, T. R. (1999) “The Duty of Candor in Future Software Documentation”, $46^{\text {th }}$ Annual STC Conference, Cincinnati, Ohio. (http://www.stc.org/46thConf/postconf/girill.html, accessed 4 November, 2003)

Gotterbarn, D. (1995) "The Moral Responsibility of Software Developers: Three Levels of Software Engineering”, Journal of Information Ethics, Vol. 4, No. 1, pp 54-64., in Coleman, K. G. 2005.

Hart, H. L. A. (1985) Punishment and Responsibility, in Coleman, K. G. 2005.

Heckman, C. \& Wobbrock, J. O. (1998) "Liability for Autonomous Agents", Autonomous Agents '98, pp 392-399.

Johnson, D. G. \& Mulvey, J. M. (1995) “Accountability and Computer Decision Systems”, Communications of the ACM, Vol. 38, No. 12, pp 58-64.

Ladd, J. (1989) Computers and Moral Responsibility, in The Information Web: Ethical and Social Implications of Computer Networking, Gould, C. (ed), Westport Press, Boulder, in Coleman, K. G. 2005.

Markovsky, B. and Jin, W. (2002) “Theories, tests and computer simulations”, Presented at the 2002 Annual Meeting of the American Sociological Association (http://home.sc.rr.com/bmarkovsky/papers/ASASim02.pdf, accessed 29 June 2005).

Morgan, M. S. and Morrison, M. (1999) Models as Mediators Perspectives on Natural and Social Science, CUP, Cambridge.

Mulvey, J. M. (1994) Models in the Public Sector: Success, Failure and Ethical Behavior, in Wallace, W. A. (ed), pp 58 - 73.

Nissenbaum, H. (1994) "Computing and Accountability”, Communications of the ACM, Vol. 37, No. 1, pp. 73-80, in Coleman, K. G. 2005.

Nissenbaum, H. (1996) “Accountability in a Computerized Society”, Science and Engineering Ethics, Vol. 2, pp 25-42 in Coleman, K. G. 2005.

Ören, T. I. (2000) "Responsibility, Ethics, and Simulation", TRANSACTIONS of The Society for Computer Simulation International, 17, 4, pp 165-170.

Ören, T. I. (2002a) "Growing Importance of Modeling and Simulation: Professional and Ethical Implications", in Proceedings of the ICSC'2002 - The $5^{\text {th }}$ Conference on System Simulation and Scientific Computing.

Ören, T. I. (2002b) "Rationale for a Code of Professional Ethics for Simulationists", in Proceedings of the Summer Computer Simulation Conference.

Rogers, R. V. (1997) What makes a modeling and simulation professional?: The consensus view from one workshop, in Andradóttir, S. et al (eds) Proceedings of the 1997 Winter Simulation Conference, pp 1375-1382.

Shelly, G. B, Cashman, T. J. \& Vermaat, M. E. (2002) Discovering Computers 2003 Concepts for a Digital World, Thompson Course Technology, Boston, MA.

Singh, N. (1996) Systems Approach to Computer-Integrated Design and Manufacture, John Wiley \& Sons, New York. 
Society for Modeling and Simulation International (2005) A Code of Professional Ethics for

Simulationists (SimEthics), http://www.site.uottawa.ca/ oren/SCS_Ethics/ethics.htm).

Sterman, J. D. (1991) A Skeptic's Guide to Computer Models, in Barney, G. O., Kreutzer, W. B. \& Garrett, M. J. (eds) 1991, pp 209-229.

Wallace, W. A. (ed) (1994) Ethics in Modeling, Elsevier Science, Oxford.

Weckert, J. \& Adeney, D. (1997) Computer and Information Ethics, Greenwood Press, Westport. 